\title{
Mark Carthew
}

\section{Into the labyrinth. Early career research: the academic journey and the publishing maze}

\begin{abstract}
Early Career Researchers (ECRs) can learn a great deal from the insights of philosophers such as Aristotle and Socrates, although most would not necessarily wish to emulate Socrates' aggravation of the Athenian proletariat and subsequent execution (by poisoning) for stirring the status quo.

While some similarities may appear between academic gatekeepers and the ancient Athenian hegemony, early career researchers are by definition trying to establish themselves; however, biting the hand that feeds you is a cardinal sin in both publishing and academia, as well as a poor option in achieving fulfilment of life choices.

In this reflection based on my active practitioner perspective as a PhD in writing candidate and established children's writer, I wish to explore some of the factors affecting an early career researcher's ability to find publishing outlets and forums for their work and interests. I will in turn highlight the importance of having accessible and encouraging support structures for ECRs, the body academic and publishing forums associated with the arts and writing faculty.
\end{abstract}

\author{
Men acquire a particular quality by constantly acting \\ a particular way ... you become just by performing just actions, \\ temperate by performing temperate actions, \\ brave by performing brave actions. \\ - Aristotle (384-322 BC)
}

\begin{abstract}
Regard your good name as the richest jewel you can possibly be possessed of - for credit is like fire; when once you have kindled it you may easily preserve it, but if you once extinguish it, you will find it an arduous task to rekindle it again. The way to gain a good reputation is to endeavour to be what you desire to appear.

- Socrates (469-399 BC)
\end{abstract}

\section{Avoiding a Greek tragedy}

Aristotle's insightful reflection is a pragmatic assessment of action as a defining act of self. We are as we do.

Theseus' act of courage in seeking out the Minotaur flagged his status as courageous hero. His quest and subsequent achievement were, however, aided by the intellectual cunning and prior knowledge of the resourceful Ariadne, which highlights the advantages of having 'privileged' assistance in achieving a goal; especially when the task is fraught with perplexity and challenge. Heroic testosterone and idealistic endeavour alone would not have overcome the Minotaur or the challenges of the labyrinth.

Some feminist theorists might be tempted to describe Theseus as an archetypical dependent whose success with the Minotaur quite palpably rode on the back of the fairer sex's insight. However, one thing remains true regardless of discussions on male hegemonies, dominance and dependence (Rigby 2001: 25): i.e. an act of collaboration was needed to achieve the quest, a point that I will expand upon a little further into this paper.

Labyrinths of course are multifaceted, and their place in our cultural history is in many ways both analogous to and symbolic of the writer's journey. A descriptive excerpt from Wikipedia seems pertinent in this regard: 
Prehistoric labyrinths are believed to have served as traps for malevolent spirits or as defined paths for ritual dances. In medieval times, the labyrinth symbolized a hard path to God with a clearly defined center (God) and one entrance (birth). Labyrinths can be thought of as symbolic forms of pilgramage; people can walk the path, ascending toward salvation or enlightenment. (Wikipedia 2008)

The 'path poetica' or 'road to salvation' for an early career researcher in creative writing is one almost certainly framed by the researcher's initial guile and wherewithal on the journey towards acceptance into the academy. Mistakes in methodology or a lack of understanding of research mores, ethics processes, documentation and citing conventions are just a few of potential pits of despair that also impact on the symbiotic (albeit hopeful) potential by-product of publication. The role of a knowledgeable mentor or guide here is critical, providing the ECR access to accumulated knowledge and insights into potential pitfalls, twists and turns. The mentor or critical friend in this context is symbolic of Ariadne's ball of string - a guiding light in the darkness.

Salvation of course may be synonymous and synchronous with the affirmation and the joie de vivre that comes with acceptance of a manuscript and subsequent publication in any public forum. Enlightenment may be dependent on the recognition of key aspects of success on the road to salvation, but it can also be the result of intellectual injury marked by mistakes, failure and/or rejection.

One of the key principles of modern pedagogy is the fundamental notion that success builds success, and that the achievement of success is a cornerstone of a positive attitude to learning. This principle, espoused by internationally regarded educators such as Michael Fullan, Peter Hill and Carmel Crévola (2006), and Caldwell and Spinks (1998), informs contemporary views of the lifelong learning journey. It is therefore incumbent on educators and mentors to assist ECRs in avoiding pitfalls and 'traps' by helping them experience success in the educative and early research process. However the ability of even the most wonderful mentors to facilitate success in publishing is another story, as other forces are also at work.

\section{Publish or perish?}

Acceptance of a paper in an academic journal or conference proceeding is the pinnacle of a similar rubric in mainstream trade or education publishing, in that the public act of a manuscript's acceptance helps define the voice and persona of the 'bona fide' writer. Donna Lee Brien's opening address and session paper 'Publish or Perish? Investigating the Doctorate by Publication in Writing' (2008) at the Australian Association of Writing Programs (AAWP) Conference Creativity and Uncertainty in Sydney, Australia, explores this theme further in the context of a variety of issues related to early career research and publication, while succinctly providing a useful summation of academic publication:

In the academic research environment, publication is largely understood as peer reviewed publishing - books, book chapters, journal articles and refereed conference papers. Publication, by dictionary definition, similarly privileges print as in 'the publishing of something, especially printed material for sale' and 'an item that has been published, especially in printed form'. (Brien 2008: 4)

Writers in any genre are framed by their publication record and contribution to their field. The statement a journalist is as a journalist does may seem a little twee, but it does echo Aristotle's sentiment. While some may specialise in a journalistic style of writing and be very good at it, a writer would not usually be ascribed 'journalist' if they have never been published in a newspaper. We are all defined by our active practice; past and present. General managers, lecturers and doctors are exactly that, general managers, lecturers and doctors - not aspirants. Performance artists and musicians have similar 'defining' issues; anyone in theory can act or sing, but not all can be classed as true professional actors, musicians or singers. The obvious question ensues: must true writers write books or at least publishable manuscripts? This question resonates around the ever-burgeoning university creative writing courses and also frames the very structure of higher education research and creative writing by artefact and exegesis courses (University of Adelaide 2008). It continues to be the subject of passionate discussion at professional writing conferences (Brien 2008) and in papers such as Jeri Kroll's 
Uneasy Bedfellows article (1999), where she questions the perception of 'publishable' quality and standard from both the industry and academic perspectives (Kroll 1999).

While not wishing to become embroiled in a dissertation on the meaning of the writerly self or definitions of 'publishable' or even 'quality literature', there is no doubt that publication impacts on perceptions of a writer's credibility in both academia and the broader commercial world. Public recognition and perception of the writerly-self are framed by that outcome. The Australia Council for the Arts' tightly structured definition of emerging, developing and established writers (Australia Council for the Arts 2008: 55) is evidence of the need of a mainstream publication history in order to apply for and obtain access to arts grants. Their base level minimum entry eligibility requirements for 'emerging writers and illustrators' to apply for a new work grant is illuminating:

\section{Emerging writers/illustrators}

Amount: $\$ 5000, \$ 10,000$ or $\$ 15,000$.

Apply under this sub-category if you have achieved any of the following publication/performance requirements:

- 10 short works of fiction or literary non-fiction in professional literary journals, anthologies, general national magazines or major newspapers

- 10 prose pieces professionally performed

- 25 different poems in professional literary journals, anthologies, general national magazines or major newspapers

- 25 different poems professionally performed

- 15 different substantial articles (minimum of 1000 words each) in general national magazines or major newspapers

- Two playscripts workshopped or one short play performed under the auspices of a professional company or organisation

- Two substantial scripts (minimum 15 minutes of original text per script) or six short scripts (minimum three minutes of original text per script) broadcast on radio

- Four children's picture books or works of junior fiction (up to 30,000 words) published by a professional publisher with national distribution

- A combination of the above (such as five short stories and 13 poems).

The literature board accepts online publication where the journal:

- Uses an editorial review process and has a named editor or editorial committee, none of whom is the author

- Is freely available to the public and/or has a hard copy edition. (Australia Council for the Arts 2008)

Another recent example of this prevailing force de jour is evidenced by the Society of Children's Book Writers and Illustrators (SCBWI) head office in the USA having recently added 'PAL' to its expanding listing of member writers to define those members with an established publication record:

PAL membership, which stands for 'Published and Listed', will exist alongside Full and Associate Membership and help to further distinguish among SCBWI's authors and illustrators. PAL Members will be those who have published or have a contract with a traditional publisher. (Wasson 2008: 4)

Pressure for such delineation from within an internationally regarded writers' peak body is evidence that not only is publication a much sought-after act of affirmation and encouragement, it is also an act of public acceptance synonymous with the label 'professional writer' or 'author'. In a frustrating act of marketplace determinism, which could be construed as nepotistic by some, a gamut of publishers (as a quick scan of major Australian and international publishing house submissions policies in the Australian Writers Marketplace reveals) refuse to accept unsolicited manuscripts. While the individual publishers' policies reflect changing business circumstances and market trends, the submission process would appear to be an increasingly 'closed shop' for aspiring writers, and often only circumvented by agents or by writers with an established or active publication history. 


\section{So where does this position the ECR?}

Barthes, in his seminal and much-quoted work The Pleasure of the Text (1989), details much about text itself, its jouissance and creative pleasures, and the journey from the writer to the reader. However, for a writer to get one's work and 'writerly bliss' to the next phase - the reaching of a broader audience and readership - the piece also needs to be published in appropriately regarded forums to attain status and acknowledgement as a writer's work.

Similar to aspiring writers in trade publishing environments, aspiring academics and early career researchers in creative writing need published 'academic' works in print as part of the journey of acceptance into the academy as a bona fide, accredited voice. In a potentially selfperpetuating cycle, an academic writer must write in and for academic publications to achieve a personal sense of accreditation and opportunities for further recognition; this in turn is reinforced by systems such as associated credit points or status for host universities as well as the self. Once the writer is accredited, it would appear only natural that the system is then more likely to accept manuscripts, paper and conference abstracts and submissions, job applications et al, and the cyclic journey towards fulfilment and acknowledgement as a writer/academic begins.

Peer review, while a topic of many papers in itself (Turner 2003), is obviously a pivotal part of the accreditation process and journey into the belly of the academy. Turner's quotation of Rennie in his overview of the peer review process will no doubt resonate for both established and early career researchers:

With all of its imperfections, carefully constructed mechanisms of peer review remain an important professional tool for assessing the merits of scholarly research, identifying weaknesses in evidence, argumentation, and research methods, detecting important research findings, and providing journal editors with useful recommendations concerning how manuscripts might be improved. (Rennie 1998, cited in Turner 2003: 182)

Turner goes on to write:

if researchers, editors, and journal readers are to maintain trust, or faith, in the integrity of peer review processes, peer reviewers need to display certain core attributes. Faith, or F.A.I.T.H. in peer review depends on five core attributes: fairness in reviewing; appropriate expertise, identifiable reviewers, timely reviews; and helpful critiques. When these core elements of peer review are absent, the integrity of the peer review process is significantly compromised. (Turner 2003: 182)

While not the principal area of investigation for this paper, cognitive, somatic and even physical anxiety associated with the peer review process for novices and the impact of peer review on ECRs is certainly worthy of further investigation. This of course can be extrapolated to the entire postgraduate experience and is not unrelated to the anxiety of submitting one's work to external examiners, although these experiences are not necessarily negative. Onwuegbuzie \& Jiao reiterate this position in their empirical study of anxiety and research achievement:

The path analysis also revealed a direct, positive path from self-perception to research performance. In addition, self-perception moderated the relationship between research achievement and academic procrastination, perfectionism, and hope. (2004: 41)

My own 'virginal' experience in writing this very paper pivoted on constructive feedback from an obviously experienced and ECR-sensitive peer reviewer; and I am in debt to the insightfully pertinent points for improvement that made expansion into a publishable paper possible. It is also relevant to note that I was also encouraged by informal feedback on the AWPN 'Working Papers' section of the website (Carthew 2008). The role of significant others in this context, including peers and critical friends, also needs to be considered alongside the role of affirmation in increasing performance and output.

Conversely, and in a vibrant subject for future papers, some anachronisms are evident across all fields of study and highlighted in the creative writing field; where individuals, institutions and academics require the kudos that comes from being recognised and published in the contemporary trade publishing environment, yet numerous highly-regarded trade and 
educational publications and publishers have been excluded from the Department of Education Science and Training lists (Department of Education, Employment and Workplace Relations 2008). However, while still a potential maze for ECRs, this situation appears to be changing and the recent statement on the Department's website regarding DEST points that places the emphasis back on universities to argue and determine the case for appropriateness of commercial publishers and refereed journals is indeed an interesting development:

Following consultation with the Higher Education Sector, the department no longer maintains the Register of Commercial Publishers. DEST will no longer accept nominations for listing on the Register and will not undertake to rule on whether a particular publishing operation meets the HERDC commercial publisher requirements. HEPs have always had the discretion to determine if a publisher meets the commercial publisher requirements regardless of whether or not the publisher was included on the Register of Commercial Publishers. As stated in the HERDC specifications, the Register is not an exhaustive list of all commercial publishing operations which satisfy the HERDC requirements. (Department of Education, Employment and Workplace Relations 2008)

There are of course many publishers that publish in areas relevant to academic writers' fields of expertise, research and interest, yet some do not attract points in the government points system of merit and acknowledgment. In juxtaposition to this paradoxical situation, an active practice record in commercial publishing would seem, at least anecdotally, highly valued among both academics and students in creative writing. This is echoed in higher education institutions, with lecturers and professors being required to have active and vibrant publications lists as part of their job prescriptions. In Australia, Brian Castro's recent appointment as the Chair of Creative Writing at the University of Adelaide is indicative of the value of an active publication record, and the credibility requirements for those in leadership positions in creative writing courses (Lane 2008: 21) and Gary Crew's appointment as Associate Professor, Creative Writing, at the University of the Sunshine Coast is another such example.

\section{Avoiding the 'knowledge void'}

The role of experienced writers such as Crew and others in creative writing courses highlights the increasing importance of active practice in mentoring. Jung's 'archetype of spirit' dovetails with this notion as 'it appears in a situation where insight, understanding, good advice, determination, planning, etc. are needed but cannot be mustered on one's own resources' (Jung 1968: 216). Like Theseus, early career researchers need insightful guidance and advice in navigating the maze of hidden traps that can make the ECR's road potentially disheartening. Precision is needed in unravelling the threads and connections in research methodology and mores. Ariadne's ball of string acted like a road map in the dark, a comforting guide to negotiate unfathomable darkness. For early career researchers, mentorship and guidance are pivotal to avoid disillusionment and despair in the process of deciphering the myriad style requirements of universities, academic organisations and publishing forums.

Complex issues ensue when seeking to define the term 'academic writer'. Aristotle said we become something by behaving that way. But what does this really mean for those ascribed this dualistic descriptor? That they are thinkers? Have an ability to read and interpret other works? Consistently generate new ideas? Have the ability to push intellectual boundaries? That they are conversant with literary discourse and the writings of other writer/academics? They are experts in their field?

No matter what discipline, one would hope that new emerging writers and voices (and, by definition, early career researchers) are simply not sucked into the business of producing the same old same old: emulating long-held lexicons, regurgitating typecast clone-like manuscripts in the moulds of previous scholars and articles; writing what they believe peer reviewers are likely to approve. The contextual need for approval leads not only to insecurity but also to a seemingly self-perpetuating cyclic dichotomy - an over-reliance on stylistically formula-matic abundant quotes from learned others (a.k.a., those nestled in the bosom of the academy) to establish 'research' credibility.

An enlightening article related to this subject is Barbara Kamler and Pat Thomson's on the business end of writing abstracts, 'Driven to abstraction: doctorial supervision and writing pedagogies' (2004). Kamler and Thomson were compelled to write the article after observing 
that 'Some of our students are not only reluctant writers, but also express a range of other emotions associated with the requirement to write - agitation, resentment, despair and fear' (2004: 195). They move on to discuss and describe various factors acting upon students that evoke such negative emotions, and in particular they look at key journals in the literature and education fields, documenting their respective lack of instructional support guidelines for prospective submissions and writers.

A fundamental notion here is anxiety about the 'knowledge void', or lack of understanding of processes and conventions so often assumed by those already conversant with structures and mores of higher education research and publication. In this context, Plato's Socratic voice in Euthydemus (380 BC) adds a little wry wit applicable to the initial labyrinthine challenge of the academic quest:

Then it seemed like falling into a labyrinth: we thought we were at the finish, but our way bent round and we found ourselves as it were back at the beginning, and just as far from that which we were seeking at first. (Plato, cited Kerényi 1996: 92)

Kerényi expands on Plato's dialogue, saying:

When a dancer who follows a spiral - whose angular equivalent is precisely the meander - he returns to his starting point. Both the spiral and the meander are to be taken as paths on which one involuntarily goes back to the beginning. Thus the present-day notion of a labyrinth as a place where one can lose one's way must be set aside. It is a confusing path, hard to follow without a thread, but, provided one is not devoured at the midpoint, it leads surely, despite twists and turns, back to the beginning. (1996: 92-93)

Kamler and Thomson's commitment to a sound pedagogical framework resonates powerfully. Fundamental principles apply: we learn through 'doing', and in positive, affirming environments. Negative environments that act as blockers cannot possibly be productive ... or desirable.

'Knowledge void syndrome' and the associated insecurity would appear to be not uncommon on entry into postgraduate study. Onwuegbuzie and Jiao (2004) refer to Onwuegbuzie's 1997 study concerning anxiety and research proposals when writing that:

library anxiety associated with affective barriers and knowledge of the library were both moderate predictors of graduate students' ability to write a research proposal. That is, students who attained the lowest levels of performance for their research proposals tended to have high levels of library anxiety associated with affective barriers and knowledge of the library. (Onwuegbuzie \& Jiao 2004: 42)

While they write that there is a lack of research in this area, it would also seem reasonable to contextualise the results of this research with similar anxiety associated with other aspects of the academic knowledge and achievement spectrum for early career or novice researchers. Jen Webb's recent Australian Postgraduate Writers Network (APWN) survey of PhD students who were asked to describe what/who helped or hindered their learning also provides some indication of the range of divergent, yet common anxieties and insecurities from postgraduate students and early career researchers (Webb 2008).

While all new ventures by definition involve a degree of anxiety and learning curve behaviours, anecdotal evidence from personal and online conversations with fellow $\mathrm{PhD}$ students, and surveys such as conducted by Webb, seem to indicate a degree of congruence with an unjustifiable, yet imaginable conspiracy theory: that is, that the notion of 'total independence' a.k.a 'work it out yourself' is a part of a plan to initiate new researchers and novices into academic rigour; possibly on the pretext of ensuring integrity on the path to enlightenment. However it is interesting that, in Australia, higher education institutions have formed an interwoven body of support services such as Academic Language and Learning centres (see Barthel 2008) to assist students in this regard.

Luckily for me, like Theseus I have been blessed with inclusive, knowledge-sharing mentors. Fellow students, supervisors and a broadening network of significant others continue to assist my journey through the academic maze; and the first two stanzas of Matthew Arnold's evocative poem Self-Dependence (1852) resonate in this regard: 
Weary of myself, and sick of asking

What I am, and what I ought to be,

At this vessel's prow I stand, which bears me

Forwards, forwards o'er the starlit sea.

And a look of passionate desire

O'er the sea and to the stars I send:

Ye who from my childhood up have calmed me,

Calm me, ah, compose me to the end! (Arnold 1913: 165)

As an academic novice I am grateful for calming balms. Simple things can be confusing and daunting when first encountered, such as a first kiss, or an attempt to put together something complex, without instructions. For ECRs the academic 'first kiss' can be as simple as not understanding the basic principles of how to write quality, publishable abstracts. Kamler and Thomson (2004) clearly enunciate an example of that void by describing in their research the decided lack of instructions from journal editors regarding the writing of abstracts and article foci that has produced a confusing, 'motley and often bland array of conventions and genres' (Kamler and Thomson 2004: 207). Enlightened journals and organisations have an important role to play by not only providing clear instructions but by also being prepared to encourage contributions by new voices and novice researchers.

As an early career research journeyman moving towards an academic voice, I was greatly heartened by my involvement in a recent online synchronous interactive workshop hosted by the APWN; as a step towards establishing self-confidence in conversational dialogue with established academics as colleagues and mentors. Such informal interactions and forums sow many seeds and contribute to an evolving understanding of academic conversations.

Presentations and audience membership at research colloquia have also played an important role as an affirming experience; building further insights into repertoire and style. Colloquia can also contribute to the sense of collegiate belonging, an issue for all academics, no matter what their status, experience or area of expertise. Greater access to colloquia across universities and campuses would be one way of fertilising and encouraging the cross-pollination of ideas and dialogue.

\section{New technologies, new windows}

In my own research journey it would appear that existing structures for journal articles, conference papers and thesis writing appear to encourage repetition or emulation of what has gone before. There are, however, positive signs in journal publications of increased experimentation in style, and it is up to conference paper selection panels and editorial committees of journals to affirm best practice education pedagogy by encouraging dissertations and papers that contribute to knowledge by exploring outside the existing square. It is in this context that I would assert that the ability or rather inability to experiment within the confines of academic publishing's seemingly formula-matic structure is a very real issue for ECRs.

Following protocols is obviously a prerequisite consideration for anyone wishing to write a refereed paper and while a novice in this regard, I have no doubt my own desire to more fully understand protocol requirements would be echoed by many other ECRs, a point that was also evident in Webb's 2008 AWPN survey. It is therefore tremendously heartening to see articles such as Shane Smith's recent innovative article 'Academaesthetics: How the essay and comic can save each other' (2007) utilizing cartoon images to deliver stimulating ideas in cutting edge, contemporary manner. 


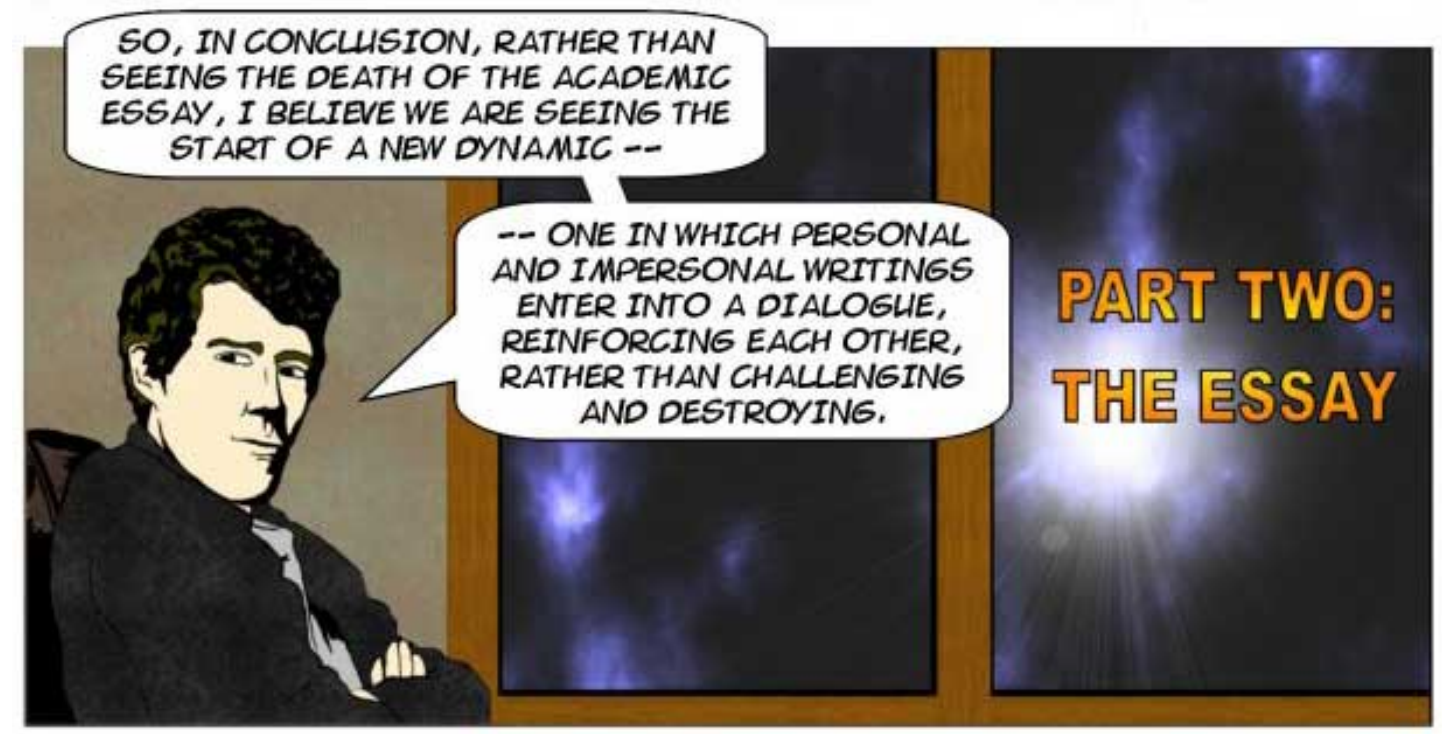

(image reproduced from Smith 2007: 30)

ECRs need role models such as this to encourage a sense of validity for varied techniques and modes of delivery.

Michael Wilding, University of Sydney's Emeritus Professor in the School of Letters, Art and Media, also provides a valuable role model for excellence in contemporary academic writing in his article 'Teaching Writing' in TEXT (2007). This article uses a conversational, fictional writing style to achieve a cleverly crafted message, without the use of 'tired formulae' or the necessity for copious referencing. It is readable as an act of pleasure and appreciation of the writer's gift. While it is decidedly unfair to take such a small piece from an engaging and thought-provoking narrative, Michael's first sentences act as an abstract, providing a teasing hint of the intriguing dialogue to come:

They sat in the Korean barbeque. Dr Bee's dead cow sizzled on the grill on the table, succulently for Dr Bee, noxiously for Pawley. Henry expressed no opinion. It had been indicated to him that his views were better left

unexpressed. Unanimously indicated by the Writers' Centre Director, by the Festival Director, by the Ministries, both Arts and Health, and, historically, by the University. He sat in momentary silence. Pawley had ordered dol sot bib-im-bab. Without meat. Egg?

'Up to four eggs a week are good for you,' Dr Bee informed them.

'They used to be bad for you,' said Henry.

'They've changed their mind. They've found they actually reduce cholesterol,' said Dr Bee. (Wilding 2007)

Such examples of innovative writing from established writer/academics provide wonderful affirmation and inspiration to ECRs uneasy about taking risks or experimenting with technique. They also highlight the enormous value of contemporary, proactive journals such as TEXT and others that encourage and affirm stylistic variation within their normal quality control and editorial processes.

Modern communication's exponential development continues to expand into new modes of communication combining text, image and sound. Journals and associated papers need to embrace all the opportunities to add value and breadth to academic forums (Pederson 2008). Aristotle and Plato would have doubtless enjoyed the enormous benefits of multimedia in the modern age and the benefits of using supplementary imagery to extol a point with visual imagery. Picasso's Minotaur of course triggers many more conceptual connections when we visualise the image (Goldstein and Harborne 1999). Jungian psychology aside, best practice pedagogy based on Howard Gardner's theories of learning via multiple intelligences (1993) demands that educators at all levels take into account the various learning styles of individuals which includes visual learners. These styles don't just magically disappear once adult metamorphosis and 'academic crystallis' take place.

The ability actually to see Picasso's enormous range of artistic visualisations in the Minotaur series is only truly appreciated by the visualization itself (Monroy et al 2003). The power of hypertext is a terrific example of this knowledge dissemination immediacy linked with learning 
styles, for as the author of this article, it would be my desire to transport all readers into the exciting visual imagery of the online Picasso project at http://picasso.tamu.edu/picasso led by Enrique Mallen (2008) directly at this point in the reading process.

While the quality of writing and subsequent enlightenment communicated to others is the litmus test by which writers are ultimately judged, a failure to embrace the potential of reaching an audience with an appetite for and learning styles enhanced via visual imagery would seem counterproductive. Pedersen, in her excellent article on the use of images in the production of relations and meaning, argues that:

the inclusion of pictorial material is a useful way to develop poststructuralist thinking technologies to further expand our understandings of the complexities of communication in individual as well as collective sensemaking. (Pedersen 2008: 35)

If we assume that research articles and commentary are written not only as a contribution to knowledge, but as a form of engagement with the reader, then it seems logical to use as many techniques as possible to add meaning and value. Pederson affirms this point by quoting Kjørup: 'in comparison with linguistic systems, one could say that images have a broader and more open content than one single word or sentence' (Kjørup 1991, cited Pedersen 2008: 36).

While Pedersen goes on to detail a more comprehensive analysis of collective association with meaning in imagery, my own reason for highlighting this point is more pragmatic. As an ECR surveying potential publishing forums it seems that print-based academic journals are reticent to embrace the ever-expanding pictorial tools of communication at their disposal; and presumably missing an exciting opportunity to connect with and engage their readership and audience.

This is not just about the aesthetics of pictures or even the expense of adding images into the print process. Historically the challenges of linking text with imagery have largely hinged on cost and technological issues, as Ramírez et al (2007) have contended:

Through much of the 20th century, the cost in time and resources to produce illustrations (hand drawn, or film photographed) and to publish them remained too high to permit copious use of images. Inability to document and disseminate morphological data, in turn, led to huge losses of comparative knowledge as generations turned over. Successive generations of specialists had to reevaluate that information. Information could not be efficiently preserved or disseminated. (Ramírez et al 2007: 283)

Digital technologies have moved forward at such a rate that it has changed the way we research, print and share information. We now have the potential to resurrect archival material and share and disseminate imagery to broad audiences, presenting exciting opportunities for researchers in all fields. With the advent of ever-expanding access to online journals and articles, the potential for researchers to include sound files and other multimedia devices linked to or embedded in articles is enormous. However, early career researchers searching for role models in constructing articles and related dissertations appear confronted by academic styles, constraints and models constructed by frames of reference slow to embrace new technologies. My own research of potential forums for journal article or papers indicates congruence in expected writerly style, with a strong cross-referencing citation base and an insistence on lengthy word count parameters. In what would be an ideal subject for further quantitative research, it would appear from informal discussion with editors and colleagues that a 'normal' expectation for a journal paper is approximately 5000-8000 words. Kamler and Thomson's research into editorial briefs and the vagaries of word count guidance regarding abstracts could easily be extrapolated into the nature and content of journal articles and conference papers.

As an early career researcher I am challenged by the notion that word count equates with rigour and quality. Short story as a genre both hones and exposes the wordsmith's skills; and of course the path poetica is not dependent on word count for the poet. In a potential topic for another paper I would argue that the opportunity and challenge are there for editors of journals to broaden their word count parameters to help re-position the concept of 'article' or 'paper' in the academic writerly psyche.

Supervisors, academic leaders, editors and mentors in the arts and creative writing field have a pivotal and exciting role to play in encouraging ECRs to experiment and find their own engaging, quality voice using whatever communicative techniques are at their disposal. Online 
forums, blogs, asynchronous or synchronous discussion, journals, conferences and workshops are all part of a vibrant academic discourse that includes refereed and nonrefereed papers. While not all of these forums may translate into formal academic publishing, they most certainly provide opportunities for early career researchers and writers to hone their skills and negotiate the metaphoric maze of academic mores.

\section{And so in conclusion...}

For the body academic to reflect best practice principles of equity and opportunity, there needs to be strong and prolific investment in the provision of innovative, vibrant publishing forums in print and online media, that are inclusive of new technologies and writing styles. The challenge for those already established in the academy is clear; there is a vital imperative to broaden forums and create publishing opportunities that encourage the career pathways, knowledge base and interactions of existing and future researchers. The challenge for early career researchers negotiating the academic maze and the winding road into both academic and mainstream publishing is framed by a delightful Cartesian duality for which Plato, Aristotle and indeed Theseus would no doubt have smiled knowingly:

To find one's way out of a labyrinth, one has to first find the way to its centre.

\section{List of works cited}

Arnold, Matthew 1913 The Poems of Matthew Arnold, 1840-1867 (intro Sir Arthur Quiller-Couch), Oxford: Oxford University Press return to text

Australia Council for the Arts 2008 Support for the arts handbook Australian Government, http://www.australiacouncil.gov.au/grants/grant_items/new_work__literature (accessed 1 January 2009) return to text

Barthel, Alex 2008 'Welcome to AALL', Association for Academic Language and Learning, http://www.aall.org.au/home (accessed 30 December 2008) return to text

Barthes, Roland 1989 The pleasure of the text (trans Richard Miller), New York: Noonday Press return to text

Brien, Donna Lee 2008 'Publish or perish?: investigating the doctorate by publication in writing', The Creativity and Uncertainty Papers: the refereed proceedings of the 13th conference of the Australian Association of Writing Programs, http://aawp.org.au/files/Brien.pdf return to text

Caldwell, Brian and Jim M Spinks 1998 Beyond the Self-Managing School, Abingdon Oxon: Routledge return to text

Carthew, Mark 2008 'Early career research', Australian Postgraduate Writers Network, http://www.writingnetwork.edu.au/working-papers (accessed 31 January 2008) return to text

Department of Education, Employment and Workplace Relations 2008 'Higher education research data collection', Australian Government, http://www.dest.gov.au/sectors/research sector/online forms services/ higher_education_research_data_collection.htm\#Closed--Register_of_Commercial_Publishers (accessed 30 December 2008) return to text

Fullan, Michael, Peter Hill and Carmel Crévola 2006 Breakthrough, Thousand Oaks CA: Corwin Press return to text

Gardner, Howard 1993 Multiple intelligences: the theory in practice, New York: Basic Books return to text

Goldstein, Ralph and Barbara Harborne 1999 'Picasso's Minotaur series reconsidered in the light of animus and anima', in R Goldstein and SR Bach (eds), Images, meanings and connections: essays in memory of Susan R Bach, Einsiedeln: Daimon Verlag, 187 return to text

Jung, CG 1968 The archetypes and the collective unconscious: the collected works of C.G. Jung (trans RFC Hull), v9, pt1 (Bollingen series), Princeton NJ: Princeton University Press return to text

Kamler, Barbara and Pat Thomson 2004 'Driven to abstraction: doctoral supervision and writing pedagogies', Teaching in Higher Education 9.2: 195-209 return to text

Kerényi, Carl 1996 Dionysos: archetypal image of indestructible life (trans Ralph Manheim), Princeton NJ: Princeton University Press return to text

Kroll, Jeri 1999 'Uneasy bedfellows: assessing the creative thesis and its exegesis', TEXT 3.2 (October), http://www.textjournal.com.au/oct99/kroll.htm return to text 
Mallen, Enrique 2008 The On-line Picasso Project, Texas A\&M University, http://www.tamu.edu/mocl/picasso/ (accessed 31 December 2008) return to text

Monroy, Carlos, Richard Furuta, Eduardo Urbina and Enrique Mallen 2003 'Texts, images, knowledge: visualizing Cervantes and Picasso', in John Frow (ed), Proceedings of the visual knowledges conference, University of Edinburgh Institute for Advanced Studies in the Humanities, http://webdb.ucs.ed.ac.uk/malts/other/VKC/dsp-all-papers.cfm return to text

Onwuegbuzie, Anthony J and Qun G Jiao 2004 'Information search performance and research achievement: an empirical test of the anxiety-expectation mediation model of library anxiety', Journal of the American society for information science and technology 55.1: 41-54 return to text

Pedersen, Christina Hee 2008 'Anchors of meaning - helpers of dialogue: the use of images in production of relations and meaning', International journal of qualitative studies in education 21.1: 35-47 return to text

Ramírez, MJ, JA Coddington, WP Maddison, PE Midford, L Prendini, J Miller, CE Griswold, G Hormiga, P Sierwald, N Scharff, SP Benjamin, and WC Wheeler 2007 'Linking of digital images to phylogenetic data matrices using a morphological ontology', Systematic Biology 56.2: 283-94 return to text

Rennie, B 1998 'Freedom and responsibility in medical publication: setting the balance right', JAMA 280: 300-302 return to text

Rigby, Kate 2001 'The goddess returns: ecofeminist reconsiderations of gender, nature and the sacred', in F DevlinGlass and L McCredden (eds), Feminist poetics of the sacred: creative suspicions, New York: Oxford University Press return to text

Smith, SW 2007 'Academaesthetics: how the essay and comic can save each other', TEXT 11.2 (October), http://www.textjournal.com.au/oct07/smith.htm return to text

Turner, Leigh 2003 'Promoting F.A.I.T.H. in peer review: five core attributes of effective peer review', Journal of academic ethics 1.2: 181-88 return to text

University of Adelaide 2008 Master of Arts by Research CREATIVE WRITING Discipline of English Handbook 2009 http://www.hss.adelaide.edu.au/creativewriting/program/postgrad/ CWMAResearchHandbook2008.doc (accessed 1 January 2009) return to text

Wasson, Sam 2008 'Introducing PAL: A new level of SCBWI membership', The SCBWI Bulletin (Society of Children's Book Writers and Illustrators), Nov/Dec: 4 return to text

Webb, Jen 2008 'Report on APWN: 19 November 2008', at Australian Postgraduate Writing Network, http://www.writingnetwork.edu.au/content/part-b-research-relationship (accessed 14 December 2008) return to text

Wikipedia 2008 'Labyrinth', http://en.wikipedia.org/wiki/Labyrinth (accessed 14 December 2008) return to text

Wilding, Michael 2007 'Teaching writing', TEXT 11.2 (October), http://www.textjournal.com.au/oct07/wilding.htm return to text

Mark Carthew is an award-winning children's author, editor and teacher. In 2006 Mark was awarded a three-year Australian Postgraduate Scholarship to pursue his PhD in writing at Swinburne University, Victoria, Australia. Mark also tutors in the Master of Arts (Writing) course at Swinburne University, Lilydale, Victoria. Mark's latest books include Can you keep a secret? Timeless rhymes to share and treasure (Random House - CBCA 2009 Early Childhood Notable Book), Wicked Wizards \& Leaping Lizards, illustrated by Mike Spoor (Random House), Five Little Owls illustrated by Mini Goss, and The Gobbling Tree illustrated by Susy Boyer (New Frontier).

\section{TEXT}

Vol 13 No 1 April 2009

http://www.textjournal.com.au

Editors: Nigel Krauth \& Jen Webb

Text@griffith.edu.au 